\title{
A Comparative Study of Harmonic Scalpel versus Electrocautery Dissection in Modified Radical Mastectomy
}

Dr. Rajkumar Chejara ${ }^{1}$, Dr. Ranjithkumar $\mathrm{M}^{2 *}$, Dr. S VArya ${ }^{3}$

\author{
${ }^{1}$ Associate Professor, Department of General Surgery, Safdarjung Hospital, VMMC, New Delhi, India \\ ${ }^{2}$ Post Graduate Student, Department of General Surgery, Safdarjung Hospital, VMMC, New Delhi, India \\ ${ }^{3}$ Professor, Head of Department, Department of General Surgery, Safdarjung Hospital, VMMC, New Delhi, India
}

DOI: $10.36347 /$ sasjs.2020.v06i06.004

| Received: 20.04.2020 | Accepted: 27.04.2020 | Published: 30.06.2020

*Corresponding author: Dr. Ranjithkumar M

Abstract

Original Research Article

Breast cancer is one of the leading cancer in Indian females accounting for large incidence and prevalence of any cancer type. Breast cancer management is multidisciplinary and includes surgery, chemotherapy, radiotherapy, hormonal therapy. Despite the emergence of breast conservative surgery, modified radical mastectomy still remains the commonly performed surgery for breast cancer in India .Conventional dissection by electrocautery in MRM is associated with certain degree of operative morbidity when compared to ultrasonic dissection. The harmonic scalpel is now increasingly being used in various surgeries because of its inherent advantages like bloodless field and less lateral tissue injury. However, it is still not widely used in modified radical mastectomy and there are conflicting reports in the literature regarding its benefit. In this study, we evaluated the clinical outcomes between electrocautery and harmonic scalpel in modified radical mastectomy. The study result shows harmonic scalpel dissection reduces the intra operative blood loss ( $\mathrm{p}<0.001$ ) (mean blood loss in group A was $160 \mathrm{ml}$ but in group B $190 \mathrm{ml}$ ), post operative drain volume $(\mathrm{p}<0.001$, mean drain volume in group A was $718 \mathrm{ml}$ but in group B was 1076ml), and less post operative pain $(p<0.001$, mean pain score in POD 1 \&POD 7 was $4.47,1.17$ in group A but in group B it was 5.77,2.93). However no difference was found in operative time and local wound complications. These benefits seems to justify the use of Harmonic scalpel in modified radical mastectomy.

Keywords: Modified radical mastectomy, harmonic scalpel, ultrasonic dissection, electrocautery.

Copyright @ 2020: This is an open-access article distributed under the terms of the Creative Commons Attribution license which permits unrestricted use, distribution, and reproduction in any medium for non-commercial use (NonCommercial, or CC-BY-NC) provided the original author and source are credited.

\section{INTRODUCTION}

Breast cancer kills some 458,000 people each year, according to the World Health Organization, mainly in underdeveloped countries. The incidence of breast cancer in India in 2016 was 118,000 and prevalence was nearly 526,000. Over the 26 yr period, the incidence rate of breast cancer in females increased by $39.1 \%$ from $1990-2016$ with an increase observed in every state of the country [1]. Breast cancer management has seen an evolution from the radical techniques of the previous century, involving loss of the breast, skin and underlying muscle, to current practice which aims at breast preservation.In our country most of the breast cancers present at locally advanced stage and modified radical mastectomy still remains the commonly performed surgery for breast cancer [2].

The commonly used form of energy in surgical procedures nowadays is mono polar diathermy which is easy to use, cheap and effective for small vessels bleeding control. This method is associated with-some operative morbidities such as increased blood loss, seroma, wound infection, flap necrosis, hematoma, and prolonged axillary drainage in $35 \%$ to $50 \%$ patient [3]. The large raw area after a mastectomy seems to be responsible for these complications to some extent. Monopolar cautery also generate a large degree of smoke, especially if the tissues are moist, and it is not effective within a liquid pool [4].

The harmonic scalpel is an alternative to conventional vessel sealing technique. It is increasingly being used as a tool for the dissection and hemostasis. Harmonic scalpel transform the electrical energy into high frequency $(55.000 \mathrm{~Hz})$ mechanical vibrations that cuts and coagulate the tissue at the same time [5]. The ultrasonic energy produced by the harmonic scalpel causes break down of hydrogen bonds and the formation of denatured coagulum which seals off the vessels and lymphatics thus decreasing blood loss and lymphatic drainage [6]. 
Former studies have not led to any consensus thus we planned this randomized controlled trial to determine whether harmonic dissection reduces operative morbidity. The objective was to test the hypothesis that Harmonic scalpel results in less intraoperative blood loss, less postoperative pain, smaller drainage volume, shorter procedure duration, and fewer complications [e.g., necrosis, seroma, and surgical site infections (SSI)] than electro-cautery after MRM in women with breast cancer.

\section{MATERIALS \& METHODS \\ Inclusion Criteria}

The patients are women $>18$ years of age with breast carcinoma of any stage and for whom MRM had been recommended.

\section{Exclusion Criteria \\ - Blood dyscrasia \\ - Collagen diseases \\ - Infections(mammary or axillary) \\ - Ulcerated tumors \\ - Pregnancy}

A total of 64 patients participated in the study, 60 patients were chosen after applying inclusion \& exclusion criteria and divided into two groups. Two patients were excluded due to hepatic metastasis, and one patient was excluded as the patient wanted breast conservative surgery, another one patient lost in followup and didn't turn up for surgery.

Among the selected patients 4 of them belonged to T1N0M0, 11 of them were T1N1M0, 11 of them were T2N0M0, 17 of them were T2N1M0, 2 of them were T3N0M0, 11 of them were T3N1M0 and 4 of them were T4bN1M0 (taken for MRM after Neoadjuvant chemotherapy).

Among the selected 60 patients, 30 patients in group A underwent dissection using Harmonic scalpel and another 30 patients in group B underwent dissection using Electrocautery. Postoperatively all patients received Inj. diclofenac $75 \mathrm{mg}$ i.m 8hlry for pain relief.

These Patients were observed for the following clinical outcomes on day 1 , day 3 , day 7 , day 14 and day 30 .

1. Operating time, which was taken as the time from skin incision to skin closure, was measured during surgery.

2. Intraoperative blood loss, which was estimated by conventional soaked gauze technique(Blood loss during the operation was evaluated by weighing the sponge before and after use in the surgery and recorded in grams)

3. Post -op pain assessed by Visual analog scale at the end of the first $24 \mathrm{hrs}$, 7days and 14 days.

4. Duration of drain and total drain output was estimated until drain removal by drain output monitoring card.

5. The occurrence of the following wound complications observed in the postoperative period such as hematoma, flap necrosis, seroma formation, surgical site infection.

\section{STATISTICAL ANALYSIS}

Categorical variables were presented in number and percentage $(\%)$ and continuous variables were presented as mean \pm SD and median. Normality of data was tested by the Kolmogorov-Smirnov test. If the normality was rejected then the non-parametric test was used.

Statistical tests were applied as follows:

1. Quantitative variables were compared using the Independent t-test/Mann-Whitney Test (when the data sets were not normally distributed) between the two groups.

2. Qualitative variables were correlated using Chi-Square test/Fishers' Exact test.

A $p$ value of $<0.05$ was considered statistically significant. The data was entered in MS Excel spreadsheet and analysis was done using Statistical Package for Social Sciences (SPSS) version 21.0.

\section{RESULTS AND DISCUSSION}

The clinical outcomes between the groups are tabulated below. Results of our study shows there is a statistically significant difference by harmonic scalpel compared to mono-polar cautery dissection in terms of reduced intra-operative blood loss (group A- 159 \pm 8.74 $\mathrm{ml}$, group B $-195 \pm 16.14 \&$ p-value $<0.001)$, reduced post operative drain volume (group A- 718.83 $\pm 95.75 \mathrm{ml}$, group B- $1076 \pm 95.51 \mathrm{ml} \& \mathrm{p}$-value $<0.001)$, reduced early post operative pain (pain score in POD1, POD7 for group A- 4.47, 1.17 and for group B-5.57,2.93 \& p value $<0.001)$. However no statistically significant difference in operative time $(\mathrm{p}=0.43)$ and local wound complications like hematoma $(\mathrm{p}=1.000)$, seroma $(\mathrm{p}=0.195)$, surgical site infection $(\mathrm{p}=1.000)$, flap necrosis $(\mathrm{p}=1.000)$. 


\begin{tabular}{|l|l|l|l|}
\hline \multicolumn{5}{|c}{ Table-1: Comparison of clinical outcomes } \\
\hline PATEINT RECORD & $\begin{array}{l}\text { HARMONIC SCALPEL GROUP A(N=30) } \\
\text { (MEAN } \pm \text { SD) }\end{array}$ & $\begin{array}{l}\text { ELECTROCAUTERY GROUP B(N=30) } \\
\text { MEAN } \pm \text { SD) }\end{array}$ & p-value \\
\hline Age & $47.87 \pm 11.21$ & $47.47 \pm 11.32$ & 0.871 \\
\hline BMI & $28.18 \pm 2.52$ & $28.73 \pm 2.08$ & 0.36 \\
\hline Operative time & $127.4 \pm 5.46$ & $126.8 \pm 6.29$ & $195 \pm 16.14$ \\
\hline Intra operative blood loss & $159 \pm 8.74$ & $1076 \pm 95.51$ & $<.403$ \\
\hline Post operative drain volume & $718.83 \pm 95.75$ & & $<0.001$ \\
\hline
\end{tabular}

Table-2: Post operative pain score comparison (VAS)

\begin{tabular}{|l|l|l|l|}
\hline Post operative days & Harmonic scalpel group A & Electro cautery group B & p-value \\
\hline Day 1 & $4.47 \pm 0.86$ & $5.77 \pm 0.97$ & $<0.001$ \\
\hline Day 7 & $1.17 \pm 0.65$ & $2.93 \pm 0.74$ & $<0.001$ \\
\hline Day 14 & $0.07 \pm 0.25$ & $0.1 \pm 0.31$ & 0.643 \\
\hline
\end{tabular}

\section{DISCUSSION}

The harmonic scalpel is now increasingly used in various surgeries because of its inherent advantages like bloodless field and less lateral tissue injury. However, it is still not widely used in modified radical mastectomy and there are conflicting reports in the literature regarding its benefit. In this study, we evaluated the clinical outcomes between electrocautery and harmonic scalpel in modified radical mastectomy.

In our study the majority of the patients presented between 41-50 yrs of age. Mean age of patients in the Harmonic scalpel group was $47.87 \mathrm{yrs}$ and in electrocautery group was $47.47 \mathrm{yrs}$. BMI of the patients was equally distributed in both groups.

In the subgroup analysis of operative time, we found that mean operative time for electrocautery group was 126.8 minutes and for the harmonic scalpel group was 127.4 minutes. There is no significant difference in operative time $(\mathrm{p}=0.403)$. These results were comparable to the other studies by S V S Deo et al., [7] $(\mathrm{p}=0.0837)$ and $\mathrm{S}$ khan et al., [8] $(\mathrm{p}=0.49)$. However, in the study conducted by Pallavi et al., [9] stated that mean operating time was significantly longer with a harmonic scalpel $(\mathrm{p}<0.001)$. But a study by Archana et al., [10] stated that harmonic scalpel reduces the operating time $(\mathrm{p}=0.001)$. Initially, for mastectomy, harmonic scalpel may take longer time to complete the surgery, while the surgical time decreased with experience and the mean surgical time was comparable with electrocautery.

In the subgroup analysis of intra-operative blood loss, we found that mean intra-operative blood loss of harmonic scalpel group was $159.73 \pm 8.74 \mathrm{ml}$ and electrocautery group was $195 \pm 16.14 \mathrm{ml}$.P value $<0.0001$ which shows a statistically significant difference between two groups. Thus the use of harmonic scalpel significantly reduces intra-operative blood loss. These results are comparable with all other studies reviewed and two meta-analyses by Jinbo Huang et al., [11] $(\mathrm{p}<0.001)$ and Zilli Zhang et al., [12] $(p<0.05)$. This is because harmonic scalpel seals off the vessels by denatured protein coagulum achieves better hemostasis than electrocautery, which is confirmed by low blood loss.

Post operating pain is the most important element for the patient to accept any new technique. In the subgroup analysis of postoperative pain, we observed that postoperative pain score of electrocautery \&harmonic scalpel group on POD1, POD7, POD30 showed the mean pain score was 5.77, 2.93, 0.1 $\& 4.47,1.17,0.07$ respectively ,p-value of pain score was $<0.0001$. Thus the use of harmonic scalpel in MRM significantly reduces the postoperative pain compared to electrocautery. This was due to the minimal lateral thermal damage observed with a harmonic scalpel, resulting in less irritation to pain nerve endings. These results are comparable with the study by $\mathrm{S}$ Khan et al., [8] $(\mathrm{p}<0.001)$ and Archana et al., [10] $(\mathrm{p}=0.001)$ but other studies conducted by Sunil Pabri et al., [13] and Shireen RD et al., [14] ( $\mathrm{p}=0.197)$ negating the difference. This contradiction in results can be because pain estimation is subjective and varies from patient to patient.

In the subgroup analysis of drainage volume, we found mean total drain output of electrocautery group was $1076 \pm 95.51$ and mean drain output of harmonic scalpel group was $718.83 \pm 95.75$, p-value was $<0.0001$, which was statistically significant. It gives the inference that use of harmonic scalpel reduces post-op drainage volume. These results were comparable with studies by MD Faisal et al., [15] $(\mathrm{p}=0.002)$ and Rohaizak Muhammad et al., [16] $(\mathrm{p}=0.004)$ and various other studies. This is because of the fact that electrocautery not entirely effective in blocking the severed lymphatic vessels. The harmonic scalpel, on the other hand, generates ultrasonic energy, which causes breakage of hydrogen bonds and formation of denatured coagulum, thus sealing off the lymphatics. Moreover, the inflammatory reaction in the operative field is reduced, less lymphatic tissues are injured and less oozing surface produced. All these factors contributed to reducing the postoperative drainage volume. 
In the subgroup analysis of postoperative hematoma, $\mathrm{p}$ values were $=1.000$, which was statistically insignificant. There was no statistical difference in hematoma between the groups. These results are comparable with studies conducted by Shireen RD et al., [14] ( $\mathrm{p}=0.235))$ and Pallavi et al., [9] $(\mathrm{p}=1.000)$ and various other studies. Hematoma is usually a result of incomplete hemostasis. Both electrocautery and Harmonic scalpel are capable of achieving good hemostasis, hence no difference could be observed.

In the subgroup analysis of postoperative seroma after drain removal, we observed that among the patients operated by electrocautery $16.67 \%$ developed seroma and $3.33 \%$ developed seroma in the harmonic scalpel group. But p-value was 0.195, there was no significant difference in seroma on comparing both the groups. These results are comparable to other studies by Sunil Pabri et al., [13] ( $\mathrm{p}=0.999)$ and Shireen RD et al., [14] $(\mathrm{p}=0.247)$. But other studies conducted by MD Faisal et al., [15] $(\mathrm{p}=0.003)$ and Archana et al., [10] stated that harmonic scalpel reduces the seroma formation compared to electrocautery. The reason for seroma development is still not clear. It is thought to be multifactorial, apart from the surgical technique for closing severed lymphatic vessels, various other factors like body mass index (BMI), high disease burden in the axilla, time of starting postoperative shoulder physiotherapy are also implicated as a cause for seroma. This could be a reason for discordance among the studies.

In the subgroup analysis of SSI, there was no statistically significant difference in both the groups ( $p$ $=1.000)$. This result is in consonance with a study conducted by Pallavi et al., [9] $(\mathrm{p}=0.526)$. This result can be explained by the fact that Surgical site infections depend on multiple factors such as aseptic technique, wound care, and patient's comorbidity, etc.

In terms of flap necrosis, our observation shows that only one patient $(3.33 \%$ of the study group) developed flap necrosis among those who underwent mastectomy by electrocautery but in harmonic scalpel group no one developed flap necrosis. It is not statistically significant. However, a study by Ribeiro et al., stated that electrocautery leads to the high incidence of flap necrosis and he ascribed it to different operating temperatures in the two groups. Harmonic scalpel blade delivers at $80^{\circ} \mathrm{C}$ and whereas electrocautery delivers up to $400^{\circ} \mathrm{C}$, and lower temperature may deliver a more precise dissection with less severe thermal lesions [17]. Flap necrosis can't be attributed to a particular technique and various other reasons like the thickness of flap and its vascularity is the major determinant.

\section{CONCLUSION}

In this study, we compared the clinical outcomes between harmonic scalpel and electrocautery for Modified Radical Mastectomy in patients of cancer breast. It is observed that dissection by harmonic scalpel is an better surgical tool compared to mono polar cautery with various benefits such as less intra operative blood loss, less postoperative drain volume, early drain removal ,less post-operative pain.

These advantages could be achieved without any increase in operative time. However, there was no statistically significant difference in terms of hematoma, seroma, surgical site infection, flap necrosis.

\section{LIMITATION}

As our study sample size is small and clinical staging of cancer breast between the two study groups were not evenly matched, a large scale study with bigger sample size and evenly stage-matched study is warranted to come to a definitive conclusion.

\section{REFERENCES}

1. GBD 2016 Cancer Collaborators. Global, regional, and national cancer incidence, mortality, years of life lost, years lived with disability, and disabilityadjusted life years for 29 cancer groups.19902016: a systematic analysis for Global Burden of Disease study. JAMA Oncol, 2018;2706.

2. Koshy A, Buckingham JM, Zhang Y. ACT and SE NSW Breast Cancer Treatment Group. Surgical management of invasive breast cancer: a 5-year prospective study of treatment in the Australian Capital Territory and South-Eastern New South Wales. ANZ J Surg. 2005;75:757-61.

3. Vinton AL, Traverso LW, Jolly PC. Wound complication after modified radical mastectomy with tylectomy with axillary node dissection. American Journal Surgery. 1991;161:584-8.

4. Voyles CR, Tucker RD. Education and engineering solution for potential problems with laparoscopic monopolar electrocautery. American Journal Surgery. 1992;164:57-62.

5. Harold KL, Pollinger H, Matthews BD, Kercher KW, Sing RF, Heniford BT. Comparison of ultrasonic energy, bipolar thermal energy, and vascular clips for the hemostasis of small, medium, large-sized arteries. Surg Endosc, 2003; 17:1228-30.

6. Hoenig DM, Chrostek CA, Amaral JF. Laparoscopic coagulation shears: an alternative method of hemostatic control of unsupported tissue. Journal Endo Urol, 1996; 10(5):431-3.

7. Deo SV, Shukla NK, Asthana S, Niranjan B, Srinivas G. A comparative study of modified radical mastectomy using harmonic scalpel and electrocautery. Singapore medical journal. 2002 May;43(5):226-8.

8. Khan S, Khan S, Chawla T, Murtaza G. Harmonic scalpel versus electrocautery dissection in modified radical mastectomy: a randomized controlled trial. Annals of surgical oncology. 2014 Mar 1;21(3):808-14. 
9. Mittal P, Kumar A, Kaur S, Pandove PK, Singla RL, Singh J. A comparative study of the use of harmonic scalpel versus unipolar cautery in modified radical mastectomy. Nigerian Journal of Surgery. 2017;23(1):20-5.

10. Archana A, Sureshkumar S, Vijayakumar C, Palanivel C. Comparing the harmonic scalpel with electrocautery in reducing postoperative flap necrosis and seroma formation after modified radical mastectomy in carcinoma breast patients: a double-blind prospective randomized Control Trail. Cureus. 2018 Apr;10(4):e2476.

11. Huang J, Yu Y, Wei C, Qin Q, Mo Q, Yang W. Harmonic Scalpel versus Electrocautery Dissection in Modified Radical Mastectomy for Breast Cancer: A Meta-Analysis. PLoS ONE, 2015; 10(11): e0142271.

12. Zhang Z, Li L, Pang Y, Li Q, Guo C, Wang Y, Zhu C, Meng X. Comparison of harmonic scalpel and conventional technique in the surgery for breast cancer: A systematic review and metaanalysis. Indian journal of cancer. 2018 Oct 1;55(4):348-358.

13. Pabri S, Gothwal S, Khan F. Comparative Study of Harmonic Scalpel versus Electrocautery in MRM.
Scholars Journal Applied Medical Science, 2017; 5(8A):2985-2988.

14. Damani SR, Haider S, Shah SS. Comparison of modified radical mastectomy using harmonic scalpel and electrocautery. Journal of Surgery Pakistan (International). 2013 Jan;18:2-6.

15. Faisal M, Fathy H, Shaban H, Abuelela ST, Marie A, Khaled I. A novel technique of harmonic tissue dissection reduces seroma formation after modified radical mastectomy compared to conventional electrocautery: a single-blind randomized controlled trial. Patient safety in surgery. 2018 Dec;12(1):8.

16. Muhammad R, Johann KF, Saladina JJ, Harlina ML, Niza AS. Ultracision versus electrocautery in performing modified radical mastectomy and axillary lymph node dissection for breast cancer: A prospective randomized controlled trial. Med J Malaysia. 2013 Jun;68(3):205-207.

17. Ribeiro GH, Kerr LM, Haikel RL, Peres SV, Matthes AG, Michelli RA, Bailão Jr A, Fregnani $\mathrm{JH}$, da Costa Vieira RA. Modified radical mastectomy: a pilot clinical trial comparing the use of conventional electric scalpel and harmonic scalpel. International Journal of Surgery. 2013 Jul 1;11(6):496-500. 